플 Science Press Springer-Verlag

\title{
Erratum to: Effects of freeze-thaw on soil erosion processes and sediment selectivity under simulated rainfall
}

WANG Tian ${ }^{1}$, LI Peng ${ }^{1}$, REN Zongping ${ }^{1}$, XU Guoce $^{1 *}$, LI Zhanbin ${ }^{1,2}$, YANG Yuanyuan ${ }^{1}$, TANG Shanshan ${ }^{1}$, YAO Jingwei ${ }^{1}$

${ }^{1}$ State Key Laboratory Base of Eco-Hydraulic Engineering in Arid Area, Xi'an University of Technology; Xi'an 710048, China;

${ }^{2}$ State Key Laboratory of Soil Erosion and Dry-land Farming on the Loess Plateau, Institute of Soil and Water Conservation, Chinese Academy of Sciences and Ministry of Water Resources, Yangling 712100, China

Published online: 02 March 2017

(C) Xinjiang Institute of Ecology and Geography, Chinese Academy of Sciences, Science Press and Springer-Verlag Berlin Heidelberg 2017

Erratum to: J Arid Land (2017) 9(2): 234-243

doi: $10.1007 / \mathrm{s} 40333-017-0009-3$

In this Erratum, we corrected the name and grant award number of funding "the National Basic Research Program of China (2016YFC040240X)" in the Acknowledgements section. The correction is the National Key Research and Development Program of China (2016YFC0402404).

The online version of the original article can be found under doi: 10.1007/s40333-017-0009-3.

*Corresponding author: XU Guoce (E-mail: xuguoce@xaut.edu.cn) 